\title{
RANCANGAN CATU DAYA UNTUK MEMPERBAIKI PENCAHAYAAN LAMPU LED SURFACE MOUNT DEVICE
}

\section{DESIGN OF POWER SUPPLY FOR IMPROVING LED SURFACE MOUNT DEVICE LAMP LIGHTING}

\author{
Andrea Marisi, Susanto Sigit Rahardi \\ Balai Besar Bahan dan Barang Teknik, Jl. Sangkuriang No.14 Bandung \\ Email: susantosr@yahoo.com
}

\author{
Diterima: 22 April 2013 \\ Direvisi: 23 Mei 2013 \\ Disetujui: 19 Juni 2013
}

\begin{abstract}
ABSTRAK
Lampu Light Emitting Diodes surface mount device (LED-smd) merupakan salah satu teknologi pencahayaan umum dengan efisiensi energi yang tinggi sebagai salah satu solusi terbatasnya ketersediaan energi listrik yang dapat diakses dan dimanfaatkan oleh masyarakat. Untuk mendukung fungsi rangkaian LED, diperlukan rancangan catu daya untuk mendukung fungsi rangkaian LED yang telah didesain. Telah dibuat rancangan catu daya lampu LED-smd dengan pengendali arus listrik konverter Buck. Rancangan catu daya lampu LED-smd ini dapat menjadi panduan atau resep (prescription) bagi industri lampu LED Indonesia dalam inovasi produknya.
\end{abstract}

Kata kunci: catu daya, lampu LED-smd, konverter buck, desain, panduan

\section{ABSTRACT}

Light Emitting Diodes surface mount device lamp is a recent general lighting technology with high energy efficiency as one of the solution for limited source of accessed energy that used by residential citizen. To support the basic function of LED circuit, it is necessary to design a power supply that suitable for previous designed lamp. Design of power supply has been made for LED-smd lamp using Buck converter to control current supply. It can be a guidance or prescription for manufacturer for futher innovation.

Keywords: power supply, LED-smd lamp, buck converter, design, guidance

\section{PENDAHULUAN}

Kebutuhan energi listrik yang terus meningkat dan keterbatasan pasokan energi listrik oleh Perusahaan Listrik Negara (PLN) membebani anggaran negara setiap tahunnya. Selain usaha diversifikasi energi, diperlukan usaha konservasi energi untuk meningkatkan efisiensi penggunaan energi di sisi pemanfaatan (demand side). Peralatan yang menggunakan energi listrik saat ini banyak yang mempunyai efisiensi energi rendah. Konsumsi daya listrik untuk pencahayaan adalah $16 \%$ dari total konsumsi daya listrik untuk kebutuhan rumah tangga.

Pada dasarnya, industri lampu di dalam negeri merasa tertarik dengan perkembangan ini. Beberapa perusahaan telah mulai menjual produk lampu LED impor dan ada yang merakit sendiri lampu LED. Ada pula pabrikan yang mendapatkan skema rangkaian catu daya dan daftar komponen untuk kemudian melakukan pengembangan secara coba-coba (try and error). Dengan kemampuan mengelola rantai pasok dan manajemen produksi, kendala penyediaan komponen, bahan baku dan proses produksi dapat diatasi. Namun, dibutuhkan acuan yang sederhana, praktis dan ringkas untuk memulai pengembangan inovasi produk khususnya pada bagian catu daya.

Untuk mengatasi masalah efisiensi energi catu daya dan mempercepat proses desain, diperlukan solusi berupa rancangan catu daya untuk meningkatkan pencahayaan lampu LEDsmd, sekaligus sebagai panduan sederhana dan praktis bagi industri lampu LED-smd dalam negeri, terutama industri kecil dan menengah. 
Tulisan ini memaparkan panduan dan resep berdasarkan eksperimen dan pengukuran terhadap rancangan catu daya yang dibutuhkan lampu LED-smd yang telah ditetapkan sebelumnya untuk mencapai efisiensi energi yang tinggi dan suhu operasi yang terkendali. Hal ini diharapkan dapat menjadi panduan atau resep (prescription) bagi industri lampu LED dalam negeri sehingga memberikan hasil (outcome) desain produk lampu LED yang lebih hemat energi dan murah. Selain itu, panduan tersebut dapat membantu proses desain yang lebih cepat (rapid design) dan adaptif bagi industri lampu LED.

\section{BAHAN DAN METODE}

Metodologi yang digunakan dalam membahas masalah catu daya ini adalah menggunakan penelitian yang sifatnya menerangkan (explanatory research) dan memberikan resep (prescription). Panduan ini digunakan sebagai langkah awal untuk pengembangan inovasi. Untuk itu, urutan kegiatan dilakukan secara konsisten dengan keluaran adalah penjelasan mengenai bagaimana sistem dapat bekerja dan berbagai penyesuaian agar dapat diterapkan pada model lampu LED-smd.

Langkah pertama adalah mendefinisikan masalah dan batasan (constraint). Lampu LEDsmd yang telah didesain sebelumnya menggunakan 31 buah LED-smd 5050 yang dihubung seri semua. LED-smd adalah komponen yang bekerja sebagai beban arus (current load) [6]. Oleh karena itu, pengendalian arus adalah inti dari sistem catu daya yang dirancang.

Langkah kedua adalah membuat rangkaian yang bekerja dengan sebagaimana mestinya berdasarkan acuan pada datasheet IC CPC9909, $\mathrm{Xu}$, LUN dan Renbo [1-5]. Tujuannya adalah untuk mendapatkan informasi mengenai cara kerja sistem, komponen-komponen pendukung dan bagaimana teknik perakitannya. Setelah informasi tersebut diketahui, rancangan itu disesuaikan dengan kebutuhan rangkaian LEDsmd yang telah didesain sebelumnya yang menggunakan LED-smd 5050.

Langkah ketiga adalah identifikasi potensi masalah yang akan dijumpai pada perancangan catu daya secara detil. Walaupun rancangan catu daya adalah untuk model lampu LED-smd yang telah dirancang sebelumnya, panduan ini bersifat umum bagi rancangan yang menggunakan sistem serupa.
Langkah keempat adalah pengukuran, analisis data hasil pengukuran dan pembahasan. Pengukuran menggunakan metode pengukuran yang sesuai dengan kaidah pengukuran yang diterima industri dan standardisasi [7-9].

Analisis data akan melengkapi dan mendukung pembahasan. Selain itu, parameter penting seperti identifikasi dan penanganan suhu operasi perlu diperhatikan.

\section{HASIL DAN PEMBAHASAN}

Lingkup pembahasan adalah rancangan catu daya yang memiliki efisiensi energi yang tinggi menggunakan konverter Buck untuk jenis lampu LED tanpa peredup (dimmer) seperti pada Gambar 1. Rancangan ini juga merupakan panduan sehingga dapat membantu pengembangan desain yang selanjutnya masuk ke proses produksi.

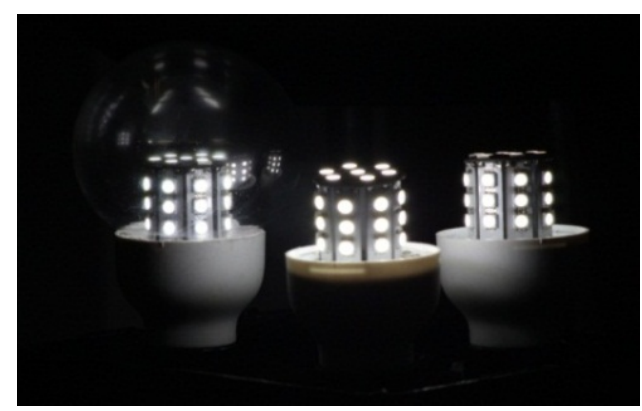

Gambar 1. Model Lampu LED Surface Mount Device

Pada penelitian sebelumnya, telah dibuat model lampu LED-smd 6 Watt tanpa peredup (dimmer) dengan menggunakan jenis LED-smd 5050 seperti pada Gambar 1 dengan rangkaian LED-smd yang telah disusun sehingga mempunyai geometri yang luas. Masalah utamanya adalah pada efisiensi konversi suplai energi listrik dari suplai jala-jala (PLN) menjadi jenis tegangan dan arus yang sesuai dengan rangkaian LED-smd. Konversi energi listrik ini dilakukan oleh catu daya atau sering disebut dengan driver yang terletak pada bagian dalam lampu. Badan lampu tersebut berbentuk sama dengan badan lampu swabalas pada umumnya. Ukuran catu daya harus sesuai dengan badan lampu yang hanya memiliki volume $63 \mathrm{~cm}^{3}$.

Telah dibuat rangkaian satu daya dengan mengikuti rangkaian tipikal pada data sheet IC CPC 9909 seperti pada Gambar 2. Rangkaian ini dipilih karena jumlah komponen yang lebih 
sedikit dan jenis produk lampu yang beroperasi tanpa perlu diawasi (unattended) sehingga tidak perlu konstruksi kelas II. Jumlah komponen yang sedikit ini memungkinkan desain pada $P C B$ yang cukup agar bisa masuk di dalam badan lampu LED-smd yang telah didesain sebelumnya.

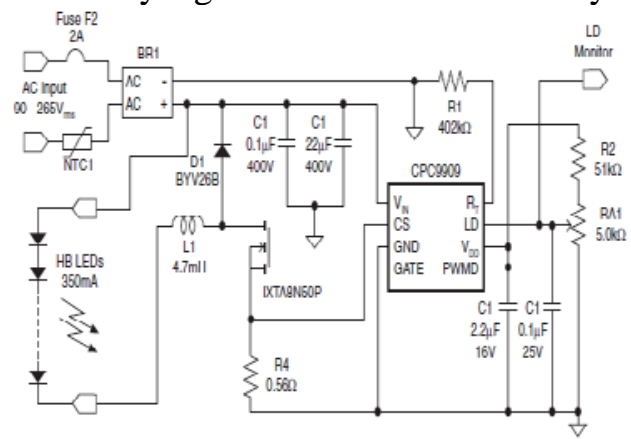

Gambar 2. Rangkaian Tipikal Catu Daya dengan IC CPC9909

Tahap selanjutnya adalah membuat rangkaian serupa dengan mempertimbangkan karakteristik beban lampu LED-smd 6 Watt. Rangkaian LED-smd dirangkai seri agar memperbesar tegangan yang diperlukan rangkaian. LED-smd 5050 adalah dioda dengan tegangan bias maju tipikal adalah 3,0 V DC dan arus operasional adalah $60 \mathrm{~mA}$.

Pada rangkaian LED-smd 6 Watt terdiri dari 31 buah LED-smd yang dirangkai seri. Tegangan yang diperlukan rangkaian LED-smd adalah 31 x 3,0 V DC = $93 \mathrm{~V} \mathrm{DC}$. Rangkaian Gambar 2 dimodifikasi menjadi rangkaian seperti pada Gambar 3.

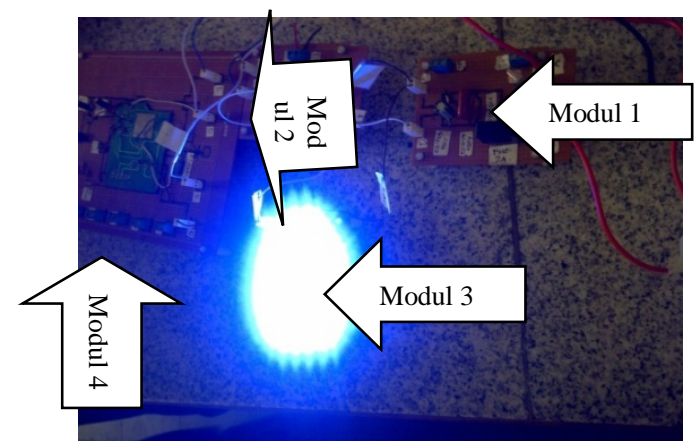

Gambar 3. Rangkaian Catu Daya yang Sudah Dimodifikasi

Rangkaian catu daya pada Gambar 3 adalah rangkaian yang sama dengan Gambar 2 . Namun, untuk mempermudah penelusuran, pengkajian dan pengembangannya, rangkaian seperti Gambar 2 kemudian diurai menjadi 4 modul. Rangkaian modul dan fungsinya adalah sebagai berikut: a. Modul 1 adalah rangkaian depan berupa penyearah dan filter. Fungsi modul 1 adalah untuk menyearahkan dan meratakan tegangan. Komponen utama pada modul 1 adalah penyearah, dan kapasitor elektrolit. Komponen keselamatan dan pendukung adalah fuse 2 A dan NTC 50K. Penyearah yang digunakan adalah DB1546. Terdapat kapasitor 0,1 $\mu \mathrm{F} 450 \mathrm{~V}$ dan kapasitor 2,2 $\mu \mathrm{F}$ $400 \mathrm{~V}$.

b. Modul 2 adalah rangkaian konverter Buck. Fungsi modul 2 adalah sebagai rangkaian konversi energi listrik yang telah disearahkan oleh modul 1.

Keluaran modul 2 adalah pada modul 3 sebagai rangkaian beban. Terdapat komponen seperti dioda $1 \mathrm{~N}$, resistor yang paralel dengan dioda $1 \mathrm{~N}$ bernilai $5,6 \Omega$, MOSFET IRF 840, induktor 4,7 $\mathrm{mH}$, dan dioda tanggap cepat BYM 260PH.

c. Modul 3 adalah rangkaian 31 buah komponen LED-smd 5050 yang dirangkai seri. Tegangan rangkaian adalah $93 \mathrm{~V} D C$ dengan arus $60 \mathrm{~mA}$.

d. Modul 4 adalah IC pengendali. IC yang digunakan adalah jenis pengendali arus hysteresis CPC9909 sebagai komponen utama. Terdapat beberapa resistor dan kapasitor sebagai komponen pendukung IC seperti Rsense bernilai 2,7 $\Omega$ dengan toleransi $1 \%$. Rsense ini digunakan untuk mendeteksi arus $60 \mathrm{~mA}$. RA1 adalah resistor yang menentukan waktu off senilai $1 \mathrm{k} \Omega$ dengan toleransi $1 \%$.

Perbandingan antara daya masukan dengan keluaran catu daya pada Gambar 3 adalah seperti yang dipaparkan pada Gambar 4.

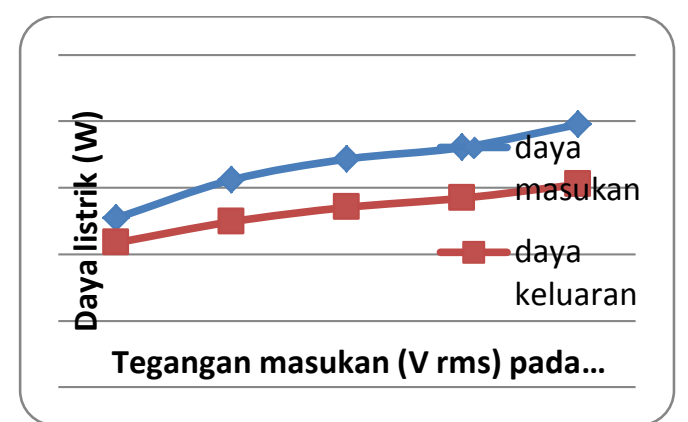

Gambar 4. Perbandingan Daya Masukan dengan

Daya Keluaran pada Frekuensi 50 Hz, dengan

Setiap Nilai Daya Terukur \pm 0,008 Watt

Efisiensi catu daya untuk tegangan masukan dari $110 \mathrm{~V}$ rms sampai $220 \mathrm{~V}$ rms pada 
frekuensi masukan $50 \mathrm{~Hz}$ adalah seperti pada Gambar 5. Efisiensi tertinggi pada tegangan masukan $110 \mathrm{~V}$ rms, yaitu 85\%.

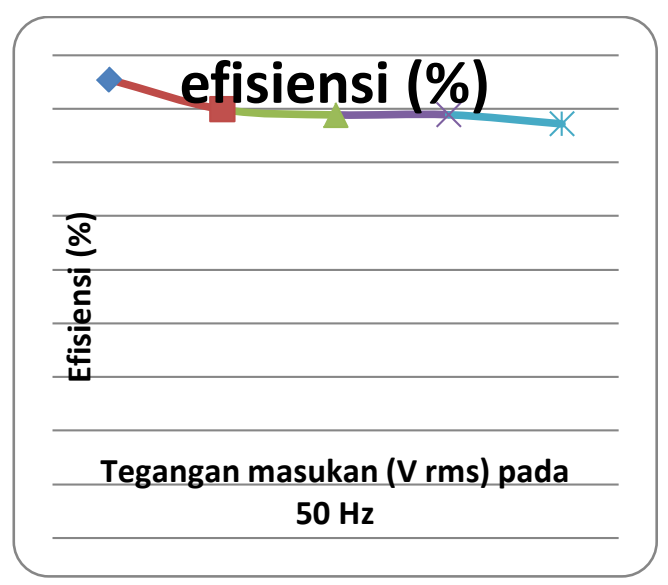

Gambar 5. Efisiensi (\%) Catu Daya

Pada selang tegangan uji $110 \mathrm{~V}$ rms sampai $220 \mathrm{~V}$ rms, perbedaan daya masukan tidak besar yaitu $(3 \pm 0,008)$ Watt dan pada daya keluaran adalah $(2 \pm 0,008)$ Watt. Hal ini menunjukkan adanya regulasi keluaran terhadap masukan.

Bila pengukuran ini dibandingkan dengan mengambil satu kondisi yaitu pada tegangan uji $220 \mathrm{Vrms} 50 \mathrm{~Hz}$, ternyata menunjukkan hasil yang tidak jauh berbeda. Pengukuran ini dilakukan menggunakan osiloskop dengan titik pada sisi Rsense $2,7 \Omega 1 \%$ yang terukur yaitu $(171 \pm 0,007) \mathrm{mV}$ eff. Dengan menggunakan Hukum Ohm didapatkan arus yang mengalir pada Rsense adalah $(63 \pm 0,06) \mathrm{mA}$ dengan daya keluaran adalah $(5,8 \pm 0,06)$ Watt. Hasil pengukuran ini dapat dilihat pada Gambar 5.

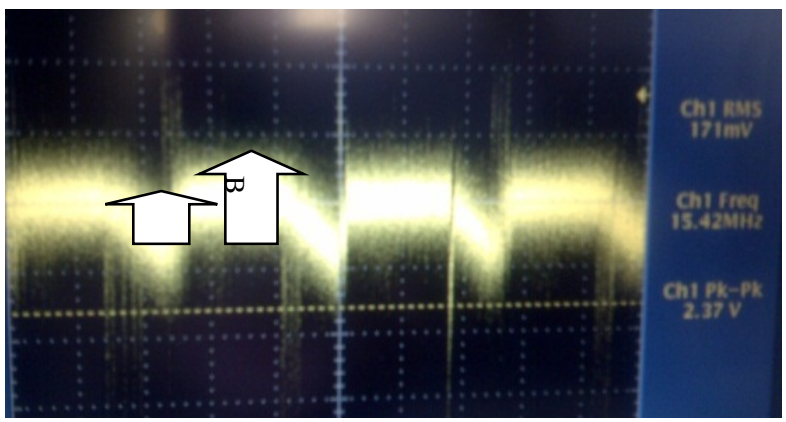

Gambar 5. Pengukuran Tegangan Rsense, dengan Posisi Pengendalian Osiloskop pada 332 Mv/DIV dan $4 \mu$ Detik

B menunjukkan adanya pengaturan arus yang mengalir pada Rsense. Dengan meng- gunakan $(171 \pm 0,007) \mathrm{mV}$ eff didapatkan arus sebesar $(63 \pm 0,06) \mathrm{mA}$. Arus ini terlalu tinggi bagi rangkaian LED-smd yang hanya memerlukan arus tipikal $60 \mathrm{~mA}$. Akibat dari arus yang melebihi ketentuan ini adalah suhu pada rangkaian $L E D$-smd yang tidak normal.

Pada tegangan uji $200 \mathrm{~V}$ rms $50 \mathrm{~Hz}$, telah dikonfirmasi melalui mengukuran menggunakan osiloskop bahwa IC bekerja memberikan pulsa kepada gerbang (gate) MOSFET seperti pada Gambar 6. Posisi pengendalian osiloskop berapa pada 5 V/DIV dan $4 \mu$ detik.

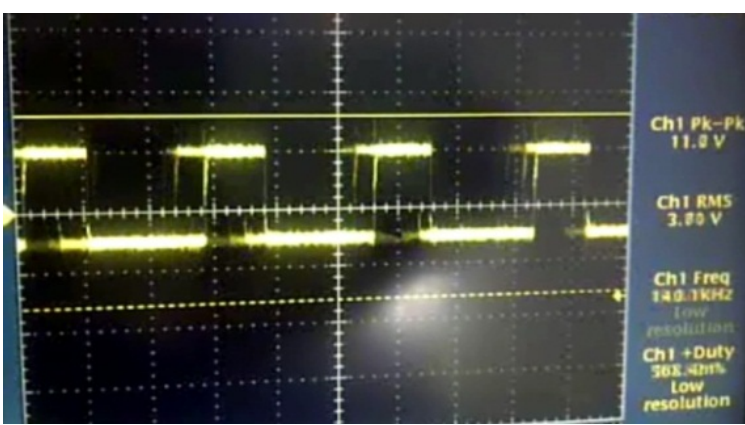

Gambar 6. Pulsa pada Gerbang MOSFET dengan Kondisi Osiloskop 5 V/DIV dan $4 \mu$ Detik dan Tegangan Uji 200 V Rms $50 \mathrm{~Hz}$

Pada tegangan uji $90 \mathrm{~V}$ rms $50 \mathrm{~Hz}$, telah dikonfirmasi melalui pengukuran menggunakan osiloskop bahwa IC bekerja memberikan pulsa kepada gerbang (gate) MOSFET seperti pada Gambar 7. Posisi pengendalian osiloskop berada pada 5 V/DIV dan $10 \mu$ detik.

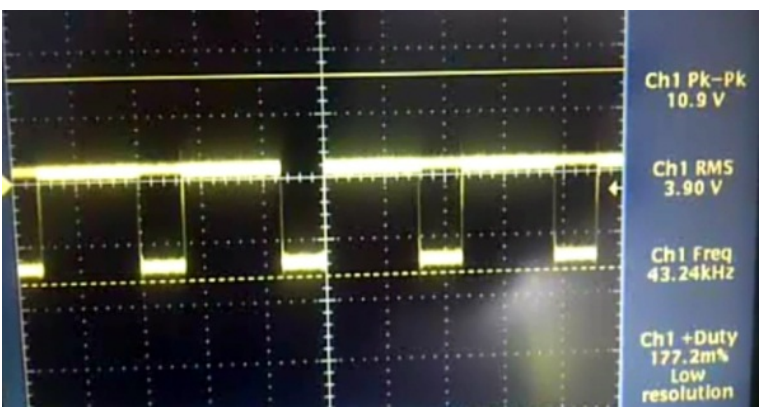

Gambar 7. Pulsa pada Gerbang MOSFET dengan Kondisi Osiloskop 5 V/DIV dan $10 \mu$ Detik dan Tegangan Uji $90 \mathrm{~V}$ rms $50 \mathrm{~Hz}$

Pulsa pada Gambar 6 dan Gambar 7 menunjukkan bahwa amplitudo adalah sama yaitu $(10,9 \pm 0,007) \mathrm{V}$ dari puncak ke puncak, namun frekuensi pulsa yang berbeda. Frekuensi ini sulit diamati karena selalu berubah-ubah. Untuk kedua kondisi di atas, kisaran frekuensi 
jauh berbeda. Hal ini mengindikasikan bahwa sistem bekerja mengkompensasi masukan agar keluaran dapat diregulasi.

Suhu yang diamati pada kondisi masukan $220 \mathrm{~V} r m s 50 \mathrm{~Hz}$ dinyatakan pada Tabel 1 berikut:

Tabel 1. Suhu pada Komponen Catu Daya (Pengukuran Suhu $\pm 2{ }^{\circ} \mathrm{C}$ )

\begin{tabular}{lc}
\hline \multicolumn{1}{c}{ Komponen } & Suhu $\left({ }^{\circ} \mathrm{C}\right)$ \\
& \\
\hline Rangkaian LED-smd (modul 3) & 75 \\
\hline MOSFET (modul 2) & 57 \\
\hline Induktor (modul 2) & 39 \\
\hline IC CPC9909 (modul 4) & 61 \\
\hline Rsense (modul 4) & 34 \\
\hline Penyearah (modul 1) & 28 \\
\hline NTC (modul 1) & 35 \\
\hline
\end{tabular}

Pada Tabel 1, IC bersuhu tidak normal. Pada Gambar 5 dan Gambar 6, tegangan gerbang adalah $11 \mathrm{~V}$ dari puncak ke puncak dan antara MOSFET dengan IC dihubung langsung. Keadaan ini membuat arus listrik pada gerbang terlalu tinggi. Untuk itu, perlu memasang resistor pada jalur gerbang IC dan MOSFET. Nilai resistor ini dipilih dengan mempertimbangkan tegangan bias maju MOSFET.

Aspek lain yang penting dalam perancangan adalah harga komponen. Harga komponen-komponen pada rangkaian catu daya pada Gambar 3 adalah Rp 50.000,- (harga pasaran di Bandung pada tahun 2012) dengan pembelian komponen secara eceran. Bila komponen dibeli secara banyak harga dapat turun secara signifikan.

Mengacu pada proses perancangan sistem catu daya ini, telah dibuat catatan-catatan sebagai panduan dalam merancang sistem catu daya jenis ini. Panduan disajikan pada urutan sebagai berikut:

1. Perhatikan sifat suplai masukan. Tegangan suplai PLN adalah $220 \mathrm{~V}$ rms dengan frekuensi $50 \mathrm{~Hz}$. Namun julat tegangan pengenal untuk mengantisipasi ketidakstabilan suplai listrik. Bila suplai bersumber dari batere 4,2 V DC, rancangan catu daya tidak perlu menggunakan penyearah.

2. Perhatikan karakteristik beban. Tentukan tegangan dan arus yang dibutuhkan beban. LED adalah komponen dioda yang bekerja berdasarkan arus. Catu daya yang dirancang adalah catu daya pengendali arus listrik. Tegangan kerja rangkaian LED sedapat mungkin dekat dengan tegangan suplai. Semakin kecil perbedaannya, semakin efisien. Bila tegangan beban lebih rendah dari pada tegangan suplai, topologi yang digunakan adalah konverter Buck. Bila sebaliknya, topologi yang digunakan adalah konverter Boost.

3. Pilihlah MOSFET yang dapat beroperasi dengan tegangan dan arus yang sesuai dengan memperhatikan spesifikasi teknik yang tertera pada datasheet. Drain to Source Voltage $\left(\mathrm{V}_{\mathrm{DS}}\right)$ harus lebih besar dari tegangan puncak suplai. Continuous Drain Current $\left(\mathrm{I}_{\mathrm{D}}\right)$ harus lebih besar dari arus suplai. Gunakan MOSFET yang memiliki kecepatan kerja yang tinggi dalam orde nano detik. Pilihlah MOSFET yang memiliki konsumsi daya rendah $\left(\mathrm{P}_{\mathrm{D}}\right)$. Pilihlah MOSFET yang memiliki Drain to Source on Resistance ( $\mathrm{r}_{\mathrm{DS}}$ ) paling rendah karena resistansi ini adalah sumber rugi daya pada MOSFET.

4. Duty cycle maksimum (D) dapat dihitung dengan cara membagi tegangan rangkaian LED (Vo) dengan tegangan minimum suplai $\left(\mathrm{V}_{\mathrm{IN}(\min )}\right)$. Misalnya tegangan rangkaian LED $93 \mathrm{~V}$ dan tegangan suplai 300, D maksimum adalah 0,31.

5. Tetapkan arus riak induktor $\Delta \mathrm{iL}$ (inductor ripple current) yang diijinkan. Arus riak induktor adalah arus puncak ke puncak pada induktor. Misalnya $30 \%$ dari arus induktor, yaitu $\Delta \mathrm{iL}=30 \%$ x $60 \mathrm{~mA}=18 \mathrm{~mA}$.

6. Tentukan Rsense dengan cara membagi VCS (high) yang didapat di spesifikasi teknis pada datasheet dengan arus rangkaian LED. Pada IC CPC9909, VCS adalah $200 \mathrm{mV}$ dan dibagi dengan arus rangkaian LED-smd $60 \mathrm{~mA}$ menghasilkan 2,9 $\Omega$. Tentukan off-time $\left(\mathrm{t}_{\text {off }}\right)$ dengan memilih RT sesuai Gambar 7.

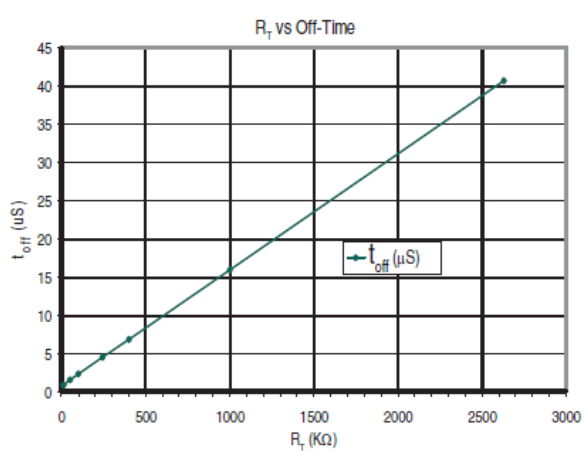

Gambar 7. Hubungan $\mathrm{t}_{\text {off }}$ dengan $\mathrm{R}_{\mathrm{T}}[5]$ 
Pada percobaan catu daya yang telah dilakukan, RT adalah $402 \mathrm{k} \Omega$. Berdasarkan Gambar 7, $\mathrm{t}_{\text {off }}$ adalah sekitar $7 \mu$ detik.

7. Frekuensi dapat dihitung dengan cara membagi (1-D) dengan $t_{\text {off. }}$ Pada catu daya ini, frekuensi adalah sekitar $100 \mathrm{kHz}$. Namun frekuensi ini menjadi tidak tetap karena bergantung pada tegangan masukan, riak pada penyearah dan riak pada induktor masuk ke pin $\mathrm{R}_{\mathrm{T}}$ sehingga mempengaruhi tegangan pada pin $\mathrm{R}_{\mathrm{T}}$. Secara praktis, frekuensi IC akan menyesuaikan dengan sendirinya.

8. Nilai minimum induktor adalah tegangan rangkaian $L E D$ dikali $\mathrm{t}_{\text {off }}$ dibagi arus riak. Pada contoh, nilai minimum induktor adalah $93 \mathrm{~V}$ x $7 \mu$ detik / $18 \mathrm{~mA}=36 \mathrm{mH}$, sedangkan yang digunakan adalah 4,7 $\mathrm{mH}$.

9. Komponen yang bersuhu tinggi dalam operasi normal adalah rangkaian LED-smd dan MOSFET. Kedua komponen ini harus menjadi perhatian utama dalam perancangan. Suhu operasi IC yang tidak normal menunjukkan ada arus yang tinggi pada IC tersebut. Untuk mengatasinya, pasang resistor pada pin gerbang yang cocok dengan tegangan bias gerbang MOSFET. Perlu dirancang desain perpindahan panas komponen-komponen catu daya pada lampu $L E D$ smd.

\section{KESIMPULAN}

Telah dirancang catu daya menggunakan sistem pengendali arus hysteresis untuk mensuplai lampu LED-smd 6 Watt yang terdiri dari rangkaian seri 31 buah $L E D$-smd 5050 yang telah dimodelkan sebelumnya. Sistem catu daya ini dipengaruhi oleh beberapa faktor yang perlu diperhitungkan. Untuk meningkatkan unjuk kerja perlu memilih komponen-komponen secara seksama. Pengukuran rancangan catu daya ini pada rentang tegangan uji $110 \mathrm{~V}$ rms sampai 220 V rms pada frekuensi $50 \mathrm{~Hz}$, menunjukkan adanya regulasi dengan efisiensi $85 \%$. Panduan dalam merancang sistem catu daya telah dipaparkan.

\section{UCAPAN TERIMAKASIH}

Penulis mengucapkan terimakasih kepada Ibu Wieke Pratiwi sebagai Kepala B4T Kementerian Perindustrian Republik Indonesia, Bapak Budi Susanto sebagai Kepala Bidang Standardisasi B4T, dan juga kepada Bapak Eko Budi Prakoso, Bapak Tridesmana, Bapak Revantino dan Indra yang telah membantu dalam penelitian ini.

\section{DAFTAR PUSTAKA}

[1] Xu et.al, 2011, Research on a HighEfficiency LED Driving Circuit Based on Buck Topology. Journal of Circuit and System,2,352-357. Published Online October 2011.

(http://www.scirp.org/journal/cs).

[2] Xu et.al, 2011, Research on a HighEfficiency LED Driving Circuit Based on Buck Topology. Journal of Circuit and System, 2, 352-357. Published Online October 2011.

(http://www.scirp.org/journal/cs).

[3] Renbo Xu, Hongjian $\mathrm{Li}$, Yongzhi $\mathrm{Li}$, Xiaomao Hou. 2011. Research On a HighEfficiency LED Driving Circuit Based On Buck Topology. Circuit and System, 2011, 2, 352-357. Scientific Research Journal.

[4] Rockis, Gary, 1993, Solid State Fundamentals For Electricians, $2^{\text {nd }}$ Edition. American Technical Publishers Inc. Illinois, USA.

[5] CPC9909 datasheet, 2012, IXYS Integrated Circuits Division. USA.

[6] 5050 SMD LED datasheet. 2011, Wayjun Technology Co., Ltd.

[7] Laboratory Procedure for Preparation, Attachment, Extension, and Use of Thermocouples, CTL-OP 108, IECEE.

[8] IRF 840 N-Channel Power MOSFET, Fairchild Semiconductor. 